\title{
Is Implant Washing and Wound Irrigation with Rifampicin Effective for Preventing Surgical Site Infections in Lumbar Instrumentation?
}

\author{
Numan KARAARSLAN', Ibrahim YILMAZ², Hanefi OZBEK², Kadir OZNAM³ ${ }^{3}$ Ozkan ATES ${ }^{4}$, Ilknur ERDEM \\ ${ }^{1}$ Namık Kemal University, School of Medicine, Department of Neurosurgery, Tekirdag, Turkey \\ ${ }^{2}$ Istanbul Medipol University, School of Medicine, Department of Medical Pharmacology, Istanbul, Turkey \\ ${ }^{3}$ Istanbul Medipol University School of Medicine, Department of Orthopaedic and Traumatology, Istanbul, Turkey \\ ${ }^{4}$ Istanbul Esenyurt University, Esencan Hospital, Department of Neurosurgery, Istanbul, Turkey \\ ${ }^{5}$ Namik Kemal University, School of Medicine, Department of Infectious Diseases, Tekirdag, Turkey
}

\section{ABSTRACT}

AIM: To determine whether the washing of implants and autogenous bone grafts with rifampicin, and the irrigation of the surgical field using diluted rifampicin, have any significant effect on the prevention of spinal implant infections.

MATERIAL and METHODS: A total of 166 consecutive lumbar stenosis and spondylolisthesis patients undergoing lumbar instrumentation between 2012 and 2016 were analyzed retrospectively. The patients were divided into two groups. Group I (n=85) included patients whose implants were washed with rifampicin immediately before insertion and whose surgical fields were irrigated with diluted rifampicin immediately after insertion. Group II $(n=81)$ included the cases without rifampicin application. Both groups were matched for age, sex, body mass index, and surgical indication. The infection rates of the groups were compared during the first 2 postoperative years.

RESULTS: No significant difference was found between the infection rate in Group I and Group II. Only 1 case had surgical site infection (SSI) in Group I, a rate of 1.17\% (1 of 85 patients), whereas 2 patients had SSI in Group II, a rate of $2.46 \%$ (2 of 81 patients).

CONCLUSION: Peroperative washing of implants with rifampicin and irrigation of the surgical field using diluted rifampicin have not been found to be significantly effective in preventing or reducing spinal implant infections. However, further studies with larger series need to be carried out to verify these results.

KEYWORDS: Implant, Infection rate, Irrigation, Spine, Rifampicin

\section{INTRODUCTION}

A pproximately $1.7 \%$ of the world population suffers from lumbar spinal stenosis and spondylolisthesis $(12,23)$. Surgical intervention is preferred for lumbar spinal stenosis and spondylolisthesis cases that do not respond to conservative and medical treatments and, particularly, exhibit signs of serious nerve compression $(9,11,22)$.
In recent studies, surgery was found to be more effective than non-surgical treatments. However, surgeries carry certain risks, such as infection, which is one of the most important postoperative complications (10). Surgical site infection (SSI) rates range from 1.7 to $15.3 \%$ (1). SSI leads to an increase in the use of antibiotics and longer hospital stays, and thus an increase in antibiotic resistance as well. Moreover, SSI imposes a serious financial burden as a result of extended antibiotic treatment periods and higher morbidity rates $(5,10)$. 
Presently, in cases where both spinal instrumentation has been performed and postoperative SSI has been observed, in addition to routine antibiotic treatments according to practice guidelines, the irrigation of the implant and surgical sites by antiseptics and/or antibiotic solutions is recommended for additional surgeries.

Washing implants and/or irrigating the surgical field with antiseptic/antibiotics, such as mupirocin, povidone-iodine solutions, and vancomycin, have been suggested for preventing or reducing deep-wound infections $(18,20,21)$. However, there has been no study in the literature about the use of rifampicin as a washing and irrigation solution in spinal instrumentation. Rifampicin, which is a cheap and easily accessible product in the market, is a bactericidal pharmacological agent used in the treatment of methicillin-resistant Staphylococcus aureus infections or mycobacteria-resistant tuberculosis and leprosy, as it inhibits ribonucleic acid (RNA) polymerase and prevents messenger RNA transcription in bacteria.

In the current study, we present the results of washing surgical implants with rifampicin and irrigating the surgical field with diluted rifampicin. We aimed to determine whether this application has any significant effect on the prevention of spinal implant infections.

\section{MATERIAL and METHODS}

The study was approved by the Local Ethics Committee of Namik Kemal University, School of Medicine.

\section{Materials}

The implants used in the operations were titanium polyaxial pedicle screws, rods, and transverse connections. The implants were made by Onplus, located in Ankara, Turkey. The pharmacological agent (rifampicin) was placed in 3-ml ampoules, each containing $250 \mathrm{mg}$ of the active ingredient, and was supplied from Kocak Farma Company, Istanbul, Turkey.

\section{Data Collection}

The data were obtained from the Material Resources and Management System of Namık Kemal University School of Medicine. The system provided all the data about the preoperative, peroperative, postoperative, and follow-up processes.

\section{Inclusion and Exclusion Criteria}

The data of 202 consecutive lumbar spinal stenosis (SS) and spondylolisthesis (SLS) patients undergoing lumbar instrumentation between 2012 and 2016 were analyzed retrospectively. However, a total of 36 patients who had immunological, rheumatic, and/or immunosuppressive diseases $(n=7)$, had received immunosuppressive treatment $(n=3)$, had received antibiotic treatment due to local or systemic infection, had used oral contraceptives $(n=2)$ or anticoagulants $(n=18)$, or had insufficient follow-up data $(n=6)$ were excluded from the study. Ultimately, 166 patients meeting the inclusion criteria were involved in the study.

\section{Indication and Surgical Technique}

Diagnosis was made based on a detailed examination. Examination of the sensory and motor functions, deep tendon reflexes, straight leg raising tests, and femoral stretch tests was carried out, and walking distance was measured for all individual cases. Lumbar X-ray, spinal computed tomography (CT) and lumbar spinal magnetic resonance imaging (MRI) scans, and electromyography (EMG) were analyzed for the purpose of diagnosis and differential diagnosis.

Both the control and study groups had been operated upon by the same surgeon. All patients underwent operation with endotracheal general anesthesia in a neutral prone position. For the purpose of prophylaxis, $1 \mathrm{~g}$ of cefazolin sodium was administered intravenously 30 minutes prior to skin incision. In all cases, the lumbar superficial fascia was incised bilaterally by means of monopolar cautery and dissected as subperiostal of paravertebral muscles by monopolar cautery. Afterward, it was found that decompression was achieved by taking the lumbar pathology level into consideration, stabilization was sustained by a transpedicular screw-rod system, and posterolateral fusion was sustained by autogenous bone grafts. Moreover, a reduction in spondylolisthesis cases, as well as surgical processes, was observed.

In rifampicin-applied cases, screws, rods, and transverse connections were washed with rifampicin in the peroperative period shortly before their implantation (Figure 1A, B). The surgical site was irrigated using a $3-\mathrm{mL}$ rifampicin solution diluted with $5 \mathrm{ml}$ of normal saline $(0.9 \%)$ after the insertion of implants but before wound closure (Figure 2).

\section{Assessment}

The patients were divided into two groups. Group I $(n=85)$ included rifampicin-applied cases, while Group II $(n=81)$ included cases without rifampicin application. Both groups were matched for age, sex, body mass index, and surgical indication. The infection rates of the groups were compared during the first 2 postoperative years. While assessing the presence of infection, the criteria determined by current guides were taken into consideration (2). Clinical and laboratory findings served as the basis for these assessments. The following symptoms were considered clinically relevant in the cases: high fever, wound discharge, rubor, low back pain or/and leg pain. C-reactive protein (CRP), erythrocyte sedimentation rate (ESR), and white blood cell (WBC) count values were evaluated by means of laboratory tests. Additionally, the cases in which MRIs were conducted and evaluated were included in this study.

\section{Statistical Analyses}

Statistical analyses were performed via SPSS 18.0 software. Data are shown with standard deviations and percentages (\%). The conformity of the digital data to the normal distribution was analyzed by a Shapiro-Wilk test: The age variable, analyzed by a Student's $t$-test, showed a normal distribution. The duration of the operation variable, analyzed by the Mann-Whitney $U$ test, did not show a normal distribution. The variables of the independent groups that were measured nominally were 


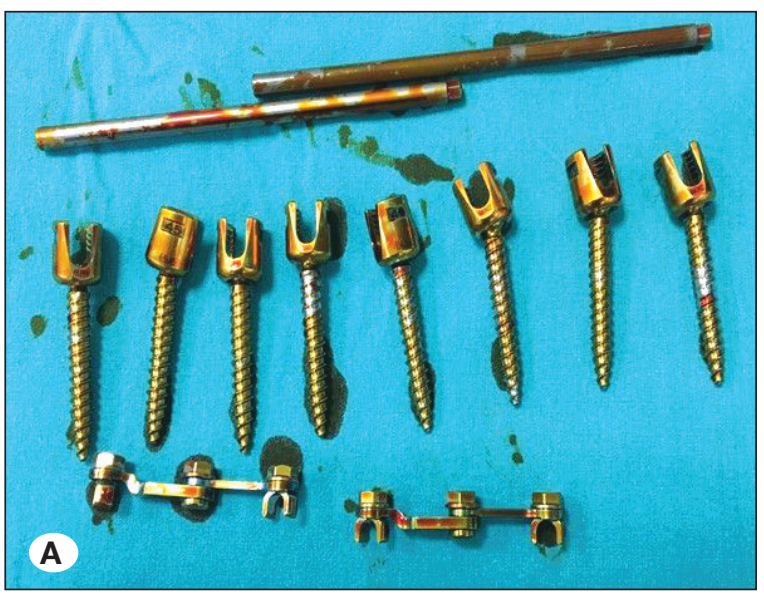

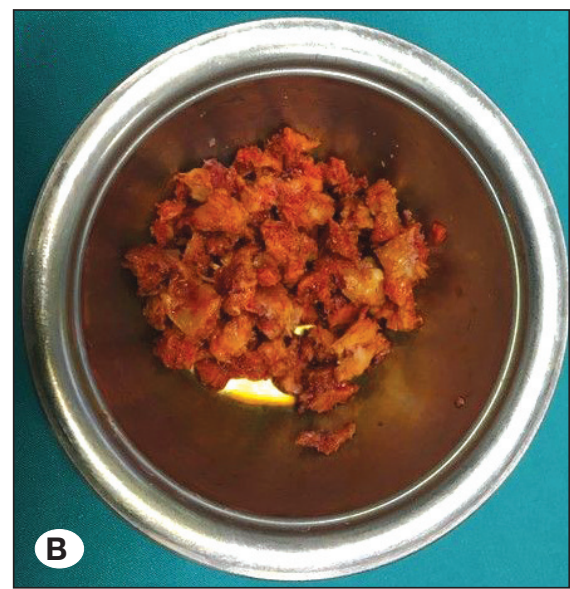

Figure 1: Perioperative images reveal (A) spinal implants (transpedicular screws, rods, and transverse bars) and (B) bone grafts washed with rifampicin before instrumentation.

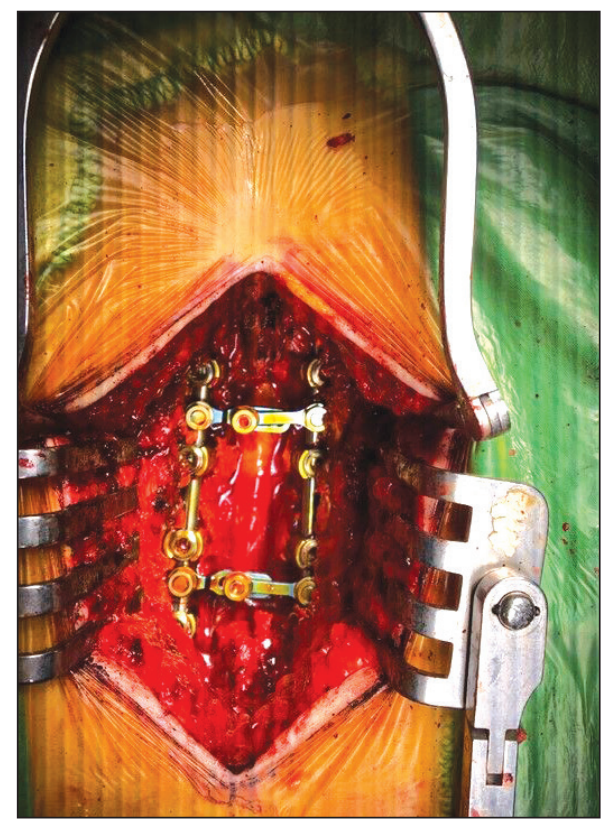

Figure 2:

Perioperative image reveals the surgical field irrigated with rifampicin after the instrumentation.

analyzed by a chi-square test. Chi-square distribution tables were formed to facilitate these analyses. In these tables, a Pearson chi-square test was used for the cases, where the rate between the cell number with an expected value less than 5 and the entire cell number was below $20 \%$. Where the rate was above $20 \%$, Fisher's exact chi-square test for four-eyed research design was used. A Monte Carlo chi-square test for the research designs with more than four eyes was also used. The possible value of $p<0.05$ was considered as significant.

\section{RESULTS}

The mean age was $59.5 \pm 9.78$ years in Group I (rifampicinapplied group). Diabetes mellitus type 2 was present in $19.7 \%$ of the cases, and hypertension was present in $39.5 \%$ of the cases. The mean duration of operation was $176.9 \pm 30.1$ minutes. The mean age was $59.35 \pm 10.15$ years in Group II (non-rifampicin group). Diabetes mellitus type 2 was present in $18.5 \%$ of the cases, and hypertension was present in $45.6 \%$ of the cases. The mean duration of operation was $175.6 \pm$ 31.4 minutes (Table I).

Only 1 case had SSI in Group I, a rate of $1.17 \%$ (1 of 85 patients), whereas 2 patients had SSI in Group II, a rate of $2.46 \%$ (2 of 81 patients).

In Group I, a 71-year-old woman with arterial hypertension (HT) and diabetes mellitus (DM) had SSI. She had undergone a 4-level instrumentation and fusion, with operation duration of 240 minutes. The microbiological assessment of the sample taken from the infection material revealed that the cause of the infection was methicillin-resistant coagulasenegative staphylococcus. She was hospitalized on the $45^{\text {th }}$ postoperative day with $13 \times 10^{9} / \mathrm{L}$ WBC, a CRP level of $70 \mathrm{mg} / \mathrm{L}$, and an ESR level of $55 \mathrm{~mm} / \mathrm{h}$. After 6 weeks of parenteral antibiotherapy, CRP decreased to $3.4 \mathrm{mg} / \mathrm{L}$ and ESR decreased to $44 \mathrm{~mm} / \mathrm{h}$ before discharge.

In Group II, a 69-year-old woman with HT and DM had SSI. She had undergone a 3-level instrumentation and fusion, with operation duration of 200 minutes. The patient underwent open abscess drainage, and the microbiological assessment of the sample revealed that cause of the infection was methicillin-resistant coagulase-negative staphylococcus. She was hospitalized on the $20^{\text {th }}$ postoperative day with $16 \times 10^{9} / \mathrm{L}$ white blood cells, a CRP level of $73 \mathrm{mg} / \mathrm{L}$, and an ESR level of $122 \mathrm{~mm} / \mathrm{h}$. After 6 weeks of parenteral and an additional 4 weeks of oral antibiotherapy, CRP decreased to $4 \mathrm{mg} / \mathrm{L}$ and ESR decreased to $18 \mathrm{~mm} / \mathrm{h}$ before discharge.

In Group II, a 42-year-old woman without any co-morbidity had SSI. She had undergone a 3-level instrumentation and fusion, with operation duration of 170 minutes. Microbiological assessment of the sample taken from the purulent wound discharge revealed that the cause of the infection was methicillin-resistant coagulase-negative staphylococcus. She was hospitalized on the $9^{\text {th }}$ postoperative day with $15 \times 10^{9} / \mathrm{L}$ white blood cells, a CRP level of $75 \mathrm{mg} / \mathrm{L}$, and an ESR level of $125 \mathrm{~mm} / \mathrm{h}$. After 4 weeks of parenteral and an additional 4 weeks of oral antibiotherapy, CRP decreased to $3.2 \mathrm{mg} / \mathrm{L}$ and ESR decreased to $50 \mathrm{~mm} / \mathrm{h}$ before discharge. 


\section{DISCUSSION}

The use of implants in lumbar stenosis and spondylolisthesis is a widely employed method in spinal surgery. Infection is one possible complication that may occur during implant surgery.
Such infections can be treated with appropriate parenteral or oral antibiotic treatment, whereas additional surgical drainage of the infected wound or removal of the infected implant materials may be needed in more complicated cases $(11,22,23)$.

Table I: Descriptive Statistics

\begin{tabular}{|c|c|c|c|c|}
\hline \multicolumn{2}{|l|}{ Variables } & Rifampicin (+) & Rifampicin (-) & $p$ value \\
\hline \multicolumn{2}{|l|}{ Age (years) ${ }^{\star}$} & $59.58 \pm 9.78$ & $59.35 \pm 10.15$ & 0.882 \\
\hline \multicolumn{2}{|l|}{ Operation time (minutes)* } & $177.71 \pm 31.22$ & $175.31 \pm 31.75$ & 0.725 \\
\hline sex & Female (\%) & $64(75.3)$ & $59(72.8)$ & 0.718 \\
\hline Hypertension (HT) & $\mathrm{HT}+(\%)$ & $34(40)$ & $37(45.7)$ & 0.460 \\
\hline Dlanetes Iviellitus (DIVI) & $\mathrm{DM}-(\%)$ & $68(80)$ & $66(81.5)$ & 0.809 \\
\hline \multirow{2}{*}{ Smoking } & Smoker (\%) & $12(14.1)$ & $16(19.8)$ & \multirow{2}{*}{0.332} \\
\hline & Non-smoker (\%) & $73(85.9)$ & $65(80.2)$ & \\
\hline Alcohol use & $+(\%)$ & $2(2.4)$ & $3(3.7)$ & 0.676 \\
\hline \multirow{2}{*}{ Infection } & $+(\%)$ & $1(1.2)$ & $2(2.5)$ & \multirow{2}{*}{0.614} \\
\hline & - (\%) & $84(98.8)$ & $79(97.5)$ & \\
\hline \multirow{2}{*}{ Spinal surgery } & $+(\%)$ & $9(10.6)$ & $8(9.9)$ & \multirow{2}{*}{0.880} \\
\hline & $-(\%)$ & $76(89.4)$ & $73(90.1)$ & \\
\hline \multirow{4}{*}{ Number of instrumented segments } & 2 Segment (\%) & $17(20)$ & $31(38.3)$ & \multirow{4}{*}{0.034} \\
\hline & 3 Segment (\%) & $44(51.8)$ & $38(46.9)$ & \\
\hline & 4 Segment (\%) & $21(24.7)$ & $10(12.3)$ & \\
\hline & 5 Segment (\%) & $3(3.5)$ & $2(2.5)$ & \\
\hline \multirow{10}{*}{ Diagnosis } & L2-3-4 SS (\%) & $5(5.9)$ & $3(3.7)$ & \multirow{10}{*}{0.001} \\
\hline & L5-S1 SLS (\%) & $2(2.4)$ & $3(3.7)$ & \\
\hline & L3-4 SS (\%) & $1(1.2)$ & $6(7.4)$ & \\
\hline & L4-5-S1 SLS (\%) & $1(1.2)$ & $0(0)$ & \\
\hline & L2-3-4-5 SLS (\%) & $1(1.2)$ & $0(0)$ & \\
\hline & L3-4-5-S1 SS (\%) & $2(2.4)$ & $0(0)$ & \\
\hline & L3-4 SLS (\%) & $2(2.4)$ & $1(1.2)$ & \\
\hline & L2-3 SLS (\%) & $1(1.2)$ & $0(0)$ & \\
\hline & L2-3 SS (\%) & $0(0)$ & $2(2.5)$ & \\
\hline & L1-2-3-4 SS (\%) & $0(0)$ & $2(2.5)$ & \\
\hline
\end{tabular}

*: (Mean \pm StD). SS: Spinal stenosis, SLS: Spondylolisthesis. 
When surgical site infections occur, they may result in longer hospitalization and additional bouts of oral or parenteral antibiotic treatment. Moreover, health expenses may increase and multidisciplinary clinicians and/or institutions may come under criticism. In a retrospective review of prospectively collected data, including 1043 patients undergoing spinal surgeries, 3 of 280 cases undergoing implant surgery resulted in infection (10). The researchers detected the SSI rate to be $1.07 \%$, which resulted in 1.5 times higher cost. In a study by Miyazaki et al. consisting of 409 cases undergoing spinal implant surgery, the SSI rate was recorded as $4.4 \%$ (14).

Deyo et al. reported the rate of deep infections to be $0.5 \%$ in patients who had undergone lumbar spine surgery (4). In another study, this rate was reported to be $1.4-3 \%(6,13,25)$. In our study, only 1 case had SSI in Group I, a rate of $1.17 \%$ (1 of 85 patients), whereas 2 patients had SSI in Group II, a rate of $2.46 \%$ ( 2 of 81 patients). In another study, SSI was reported (1.4\%) as the second-most common complication of surgeries, with the authors emphasizing that the SSI rate after implant surgeries is higher among diabetics (16). In our study, 2 of the 3 infected patients (1 from Group I and 1 Group II) had both DM and HT.

For the purpose of protecting the instrumented patients from postoperative infections, the researchers suggested the following method: peroperative intrawound irrigation with antiseptics and/or antibiotics $(18,20,21)$. Tomov et al. used a $0.3 \%$ povidone-iodine solution for wound irrigation, and the intrawound administration of $1 \mathrm{~g}$ of vancomycin powder to prevent SSI. They reported that SSI rates could be decreased by up to $50 \%$ when this mixture was used alongside the instruments immediately after wound irrigation. They also reported that methicillin-resistant Staphylococcus aureus (MRSA) decreased from $30 \%$ to $7 \%$, and multibacterial infections decreased from $37 \%$ to $7 \%$ (20).

Phillips et al. studied and compared the effects of both topical nasal mupirocine pomade and nasal povidone-iodine solution on the prevention of SSI in spinal fusion and arthroplasty operations (18). They found that topical nasal mupirocine pomade application decreases SSI by either suppressing or destroying Staphylococcus aureus colonization in nasal mucosa. Mupirocine pomade was applied in each nostril in 885 cases once a day for 5 preoperative days, and deep SSI developed in 5 cases. SSI developed in 1 out of 842 cases in the povidone-iodine group, to whom the povidone-iodine solution had been applied to each nostril within 2 hours of surgical incision. They inferred that nasal povidone-iodine could be used to decrease Staphylococcus aureus-related SSI in spinal fusion and arthroplasty operations as an alternative to nasal mupirocine (18).

Schuster et al. analyzed data from studies published between 1990 and 2007 (19). They emphasized that the infection rate decreases when the surgical field is irrigated with diluted povidone-iodine solution. Chang et al. examined 244 patients who had undergone lumbosacral posterolateral instrumentation and fusion operations (3). Patients were randomized into two groups. The study group consisted of 120 cases with 212 fusi- on levels, whereas the control group consisted of 124 cases with 212 fusion levels. The wound was irrigated with povidone-iodine solution just after bone grafting and instrumentation in Group I. The surgical field was washed with saline solution in the control group. There were 6 cases of SSI in the control group, whereas no deep infection occurred in the study group. In our study, we did not find any significant effect of rifampicin application on the prevention of SSI, although the surgical field was irrigated with diluted rifampicin solution and the implants were washed with pure rifampicin before insertion.

Yaldiz et al. retrospectively evaluated 540 cases undergoing posterior stabilization due to degenerated lumbar spine and reported 17 postoperative infection cases with different parameters (24). They concluded that the presence of systemic illness, unknown punctures in surgical gloves, and peroperative blood transfusion may increase the prevalence of post-operative infections. They underlined that SSI incidence decreases by making a prolene suture, using double gloves, and irrigating with diluted rifampicin solution.

Apart from the retrospective studies, another study carried out using living mammals demonstrated that rifampicin reduced infection (17). However, as is known, the sensitivity of human and animal tissues differs greatly, and may therefore generate misleading results. Additionally, as cell lines use single-type cells and do not have complex coordination mechanisms regarding the micro environments of cells and inhibit cell interactions, such as in the extracellular matrix, in vitro test results, which are already difficult to compare with in vivo conditions, become more controversial $(7,8,15)$.

\section{CONCLUSION}

Peroperative washing of implants and autogenous bone grafts with rifampicin, as well as additional irrigation of the surgical field with rifampicin, is not significantly effective for preventing or reducing spinal implant infections. However, further studies with larger series must be carried out to verify these results.

\section{REFERENCES}

1. Beak KH, Lee YS, Park S: The safety and decision making of instrumented surgery in infectious spondylitis. Korean J Spine 13: 120-123, 2016

2. Bratzler DW, Dellinger EP, Olsen KM, Perl TM, Auwaerter PG, Bolon MK, Fish DN, Napolitano LM, Sawyer RG, Slain D, Steinberg JP, Weinstein RA: American Society of HealthSystem Pharmacists (ASHP); Infectious Diseases Society of America (IDSA); Surgical Infection Society (SIS); Society for Healthcare Epidemiology of America (SHEA). Clinical practice guidelines for antimicrobial prophylaxis in surgery. Surg Infect (Larchmt) 14: 73-156, 2013

3. Chang FY, Chang MC, Wang ST, Yu WK, Liu CL, Chen TH: Can povidone-iodine solution be used safely in a spinal surgery? Eur Spine J 15: 1005-1014, 2016

4. Deyo RA, Cherkin DC, Loeser JD, Bigos SJ, Ciol MA: Morbidity and mortality in association with operations on the lumbar spine. The influence of age, diagnosis, and procedure. J Bone Joint Surg Am 4: 536-543, 1992 
5. Gelalis ID, Arnaoutoglou CM, Politis AN, Batzaleksis NA, Katonis PG, Xenakis TA: Bacterial wound contamination during simple and complex spinal procedures. A prospective clinical study. Spine J 11: 1042-1048, 2011

6. Imajo $\mathrm{Y}$, Taguchi $\mathrm{T}$, Neo M, Otani K, Ogata T, Ozawa H, Miyakoshi N, Murakami H, Iguchi T: Complications of spinal surgery for elderly patients with lumbar spinal stenosis in a super-aging country: An analysis of 8033 patients. J Orthop Sci 22: 10-15, 2017

7. Isyar M, Gumustas SA, Yilmaz I, Sirin DY, Tosun HB, Mahirogullari M: Are we economically efficient enough to increase the potential of in vitro proliferation of osteoblasts by means of pharmacochemical agents? Open Orthop J 10: 420-430, 2016

8. Isyar M, Yilmaz I, Nusran G, Guler O, Yalcin S, Mahirogullari M: Safety of bioabsorbable implants in vitro. BMC Surg 15: 127, 2015

9. Kim KT, Cho DC, Sung JK, Kim CH, Kang H, Kim DH: Changes in HbA1c levels and body mass index after successful decompression surgery in patients with type 2 diabetes mellitus and lumbar spinal stenosis: Results of a 2-year follow-up study. Spine J 17(2): 203-210, 2017

10. Kulkarni AG, Patel RS, Dutta S: Does minimally invasive spine surgery minimize surgical site infections? Asian Spine J 10: 1000-1006, 2016

11. Liao JC, Chiu PY, Chen WJ, Chen LH, Niu C: Surgical outcomes after instrumented lumbar surgery in patients of eighty years of age and older. BMC Musculoskelet Disord 17: 402, 2016

12. Makris UE, Edwards TC, Lavallee DC, Bauer Z, Comstock BA, Jarvik JG, Patrick DL, Lotfi M, Friedly JL: Patient priority weighting of the Roland Morris disability questionnaire does not change results of the lumbar epidural steroid injections for spinal stenosis trial. Spine (Phila Pa 1976) 42: 42-48, 2017

13. Mayer HM, Heider F: "Slalom": Microsurgical cross-over decompression for multilevel degenerative lumbar stenosis. Biomed Res Int 2016: 9074257, 2016

14. Miyazaki S, Kakutani K, Maeno K, Takada T, Yurube T, Kurosaka M, Nishida K: Surgical debridement with retention of spinal instrumentation and long-term antimicrobial therapy for multidrug-resistant surgical site infections after spinal surgery: A case series. Int Orthop 40: 1171-1177, 2016

15. Mohamed W, Sommer U, Sethi S, Domann E, Thormann U, Schütz I, Lips KS, Chakraborty T, Schnettler R, Alt V: Intracellular proliferation of $\mathrm{S}$. aureus in osteoblasts and effects of rifampicin and gentamicin on S. aureus intracellular proliferation and survival. Eur Cell Mater 28: 258-268, 2014
16. Mori K, Nishizawa K, Nakamura A, Imai S: Short-term clinical result of cortical bone trajectory technique for the treatment of degenerative lumbar spondylolisthesis with more than 1-year follow-up. Asian Spine J 10: 238-244, 2016

17. Oksuz E, Deniz FE, Gunal O, Demir O, Barut S, Markoc F, Erkorkmaz U: Which method is the most effective for preventing postoperative infection in spinal surgery? Eur Spine J 25: 1006-1011, 2016

18. Phillips M, Rosenberg A, Shopsin B, Cuff G, Skeete F, Foti A, Kraemer K, Inglima K, Press R, Bosco J: Preventing surgical site infections: A randomized, open-label trial of nasal mupirocin ointment and nasal povidone-iodine solution. Infect Control Hosp Epidemiol 35: 826-832, 2014

19. Schuster JM, Rechtine G, Norvell DC, Dettori JR: The influence of perioperative risk factors and therapeutic interventions on infection rates after spine surgery: A systematic review. Spine (Phila Pa 1976) 35: 125-137, 2010

20. Tomov M, Mitsunaga L, Durbin-Johnson B, Nallur D, Roberto $\mathrm{R}$ : Reducing surgical site infection in spinal surgery with betadine irrigation and intrawound vancomycin powder. Spine (Phila Pa 1976) 40: 491-499, 2015

21. Ulivieri S, Toninelli S, Petrini C, Oliveri G: Prevention of postoperative infection in spine surgery by wound irrigation with a solution of povidone-iodine and hydrogen peroxide. $J$ Neurosurg Sci 55: 89-92, 2011

22. Weber C, Lønne G, Rao V, Jakola AS, Solheim O, Nerland U, Rossvoll I, Nygaard ØP, Peul WC, Gulati S: Surgical management of lumbar spinal stenosis: A survey among Norwegian spine surgeons. Acta Neurochir (Wien) 159: 191197,2017

23. Whiffen JR, Neuwirth MG: Spinal stenosis. In: Bridwell KH, DeWald RL (eds), The Textbook of Spinal Surgery. $2^{\text {nd }}$ ed. Philadelphia: Lippincott Raven Publisher, 1997:1561-1580

24. Yaldiz C, Yaldiz M, Ceylan N, Kacira OK, Ceylan D, Kacira T, Kizilcay G, Tanriverdi T: Retrospective, demographic, and clinical investigation of the causes of postoperative infection in patients with lumbar spinal stenosis who underwent posterior stabilization. Medicine (Baltimore) 94: 1177, 2015

25. Yuan HA, Garfin SR, Dickman CA, Mardjetko SM: A historical cohort study of pedicle screw fixation in thoracic, lumbar, and sacral spinal fusions. Spine 19: 2279-2296, 1994 